\section{Tackling the demand for emergency department services: there are no silver bullets}

\author{
Mathew Mercuri, Shawn E Mondoux
}

A concern among ED service providers is that patient volumes and acuity are outpacing resources, prompting them to find ways to improve efficiency to meet service demands. In this issue of the Journal, Leung and colleagues ${ }^{1}$ introduce physician navigators as a novel strategy to increase emergency physician efficiency at a regional hospital in Ontario. The role of the navigator is to provide the ED physician with clerical support and assist in other organisational tasks, and their use led to an improvement in patient turnover at the study centre.

The results of this study are intuitive. A physician is limited in what he or she can do at any one time, and thus, some tasks must be completed serially. The availability of a navigator means that the physician can delegate non-clinical tasks so that he or she can effectively do two things at once. Thus, improved time-related outcomes are in keeping with the clinical process change instituted in this study. However, the physician is only part of the barrier to ED flow. Delays in registration and triage, or in other programmes such as radiology, laboratory and inpatient units may also impact flow. While the impact of such factors was beyond the scope of this study, identifying the main drivers of delay is important to realise the maximum benefit from any strategy.

Improving throughput in the $\mathrm{ED}$ is a laudable goal. Certainly, patients value a reduction in wait times, and this may lead to fewer patients leaving without being seen (an important ED quality indicator). However, one must be careful not to compromise patient outcomes in the process. Leung et $a l^{1}$ frame the benefit of navigators around the notion of improving productivity. A productive healthcare system is one that works to achieve its policy goals, which are typically focused on maximising patient important health outcomes given a

Department of Medicine, Division of Emergency Medicine, McMaster University, Hamilton, Ontario, Canada

Correspondence to Dr Mathew Mercuri, Department of Medicine, Division of Emergency Medicine, McMaster University, Hamilton, L8L 2X2 Ontario, Canada;

mercurmd@mcmaster.ca defined set of resources. The extent to which this is achieved is assessed through a measure of the quality of care. Timely care is only one of the six dimensions of a quality health system identified by the $\mathrm{WHO}^{2}$ and adopted by Health Quality Ontario (HQO). ${ }^{\mathrm{i}} 3$ The others are that care be safe, effective, patient-centred, efficient and equitable. Due to constraints in resources and measurement, studies examining the usefulness of strategies to improve service delivery often only address one or a few dimensions of quality. This might give a false impression of the real impact of the strategy, for better or worse. Likewise, addressing a component issue of a bigger problem may be a step in the right direction, but may have little impact overall, or may even have a negative effect on system performance if the solution to one problem creates a different problem elsewhere or cancels the effectiveness of some other intervention on another component in the system. We should evaluate process improvements the same way we do medications-it is not enough to show that a medication will reduce a proximate outcome. We also want to know that it will not harm the patient in the long run before we introduce it into practice.

It is important that studies examining how to optimise healthcare service delivery include balancing measures. ${ }^{4}$ For example, measures assessing improvement in turnover time should be balanced with measures of patient health outcomes and satisfaction. Downstream effects should also be considered-improving throughput in the ED is of limited value if it causes a bottleneck for inpatient services or a net increase of required services elsewhere in the healthcare system. One also needs to consider sustainability. Many positions that are common to the healthcare labour force today started out as delegated tasks from a physician

${ }^{\mathrm{i}}$ The HQO is a government mandated agency that provides advice to healthcare providers in the Province, including the hospital where the Leung et al. ${ }^{1}$ study took place. (or other healthcare professionals), only to develop into professions themselves. The navigator role 5 years from now may look very different than one today, and this might bring with it the need for specialised training (and commensurate remuneration). Furthermore, there is no guarantee that the gains seen by the implementation of navigators will be maintained as new strategies for other aspects of service delivery are introduced. Such issues change the cost /benefit structure of the strategy, making its status as a means by which to optimise quality/productivity context sensitive.

Some may see navigators as a useful strategy to improve pay-for-performance metrics. This may be true as long as such metrics are focused on wait times or patient turnover. Many jurisdictions are evolving their metrics to encompass more dimensions of quality. For example, the HQO has recently initiated a quality of care programme that focuses on return to ED within 72 hours. ${ }^{5}$ Determining the impact navigators have on this quality metric requires more than a demonstration of improved ED flow. Navigators may be proven effective in the context in which it was tested in this study, but it likely remains a fix in only part of the process that is ED care. We must take the time to evaluate the entire ED visit process, target areas for improvement, monitor our impact on other elements of care and develop important sustainability plans that objectively measure the ongoing effect of our interventions and their value to the process of care. Those organisations that address the entire process of care, by bringing together interventions such as the one described in this paper, will experience a higher likelihood of outcome success in their institutions.

Contributors Both MM and SEM contributed to drafting the commentary. Both reviewed it prior to submission.

Competing interests None declared.

Provenance and peer review Commissioned; internally peer reviewed.

(c) Article author(s) (or their employer(s) unless otherwise stated in the text of the article) 2018. All rights reserved. No commercial use is permitted unless otherwise expressly granted.

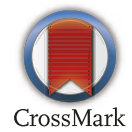

To cite Mercuri M, Mondoux SE. Emerg Med J 2018;35:3-4.

Received 11 August 2017

Accepted 21 August 2017 


\section{Commentary}

Published Online First 21 October 2017

\section{SLinked}

- http://dx.doi.org/10.1136/emermed-2017-206809

Emerg Med J 2018;35:3-4.

doi:10.1136/emermed-2017-207066

\section{REFERENCES}

1 Leung AK, Puri G, Chen BE, et al. Impact of Physician Navigators on productivity indicators in the ED. Emerg Med J 2018;35:5-11.

2 World Health Organization. Quality of Care: a process for making strategic choices in health systems. Geneva: WHO Press, 2006. http://www.who.int/management/quality/ assurance/QualityCare_B.Def.pdf (accessed on 8 Aug 2017).

3 Health Quality Ontario. Quality Matters: Realizing Excellent Care for All. Toronto: Queen's Printer for
Ontario, 2017. http://www.hqontario.ca/Portals/0/ documents/health-quality/realizing-excellent-care-forall-1704-en.pdf (accessed on 8 Aug 2017).

4 Institute for Healthcare Improvement. Science of Improvement: Establishing Measures. 2017. Available at http://www.ihi.org/resources/Pages/Howtolmprove/ ScienceofImprovementEstablishingMeasures.aspx (accessed on 8 Aug 2017).

5 Health Quality Ontario. The Emergency Department Return Visit Quality Program: Results from the first year. Toronto: Health Quality Ontario, 2017. 